\title{
CONTORNOS DA FRONTEIRA CAPITALISTA NO SÉCULO XXI: UM OLHAR SOBRE O CERRADO E A AMAZÔNIA
}

\author{
Adão Francisco de Oliveira \\ Universidade Federal do Tocantins, Programa de Pós-Graduação em Geografia, Porto Nacional, TO, Brasil \\ adaofrancisco@gmail.com \\ Rogério Castro Ferreira \\ Governo do Estado do Tocantins, Palmas, TO, Brasil \\ rogeriotrompet@gmail.com \\ Celene Cunha M. A. Barreira \\ Universidade Federal de Goiás, Instituto de Estudos Socioambientais, Programa de Pós-Graduação em \\ Geografia, Goiânia, GO, Brasil \\ celenemonteiro05@gmail.com
}

\begin{abstract}
RESUMO
O presente trabalho objetiva lançar um olhar sobre as características territoriais atuais da região Centro-Norte-Amazônica brasileira, assente sobre o Cerrado e a Floresta Amazônica, identificando os elementos que delineiam a fronteira capitalista nesse princípio de século $X X I$. Destaca a forma como as cidades médias têm servido aos preceitos capitalistas no recente processo de urbanização da região e busca relacionar as transformações ocorridas no território do Cerrado a partir da modernização imposta pelo capitalismo, por meio de uma reestruturação urbana pela qual a região Centro-Oeste tem passado desde meados do século $X X$ com o processo de expansão da fronteira econômica sobre a Amazônia. Parte-se do entendimento de que o Estado brasileiro se adequa às exigências do capitalismo mundial por meio da implantação do modelo urbano-industrial. As políticas de desenvolvimento regional implementadas principalmente após a década de 1940 viabilizaram a captura desse território pelo capital, sendo que os arranjos estatais permitiram investir em infraestrutura, criar agências de planejamento e propiciar os fluxos migratórios populacionais em direção às cidades que polarizam no território. $O$ método de abordagem é o Histórico e a análise desprendida é a Dialética, sendo que este trabalho é resultado parcial de uma pesquisa componente dos projetos "PGPSE/CAPES Desenvolvimento Territorial e Sociobiodiversidade: perspectivas para o mundo do Cerrado" e "PROCAD/CAPES Território, Meio Ambiente e Dinâmicas Rural-Urbano-Regionais na Amazônia Brasileira".
\end{abstract}

Palavras-chave: Fronteira capitalista. Políticas de Desenvolvimento Regional Urbanização. Cerrado e Amazônia.

\section{CONTOURS OF THE CAPITALIST BORDER IN THE 21ST CENTURY: A LOOK AT THE CERRADO AND THE AMAZON}

\begin{abstract}
This paper aims to take a look at the current territorial characteristics of the Brazilian CenterNorth-Amazon region, based on the Cerrado and the Amazon Forest, identifying the elements that outline the capitalist frontier in this early 21 st century. It highlights the way that medium-sized cities have served the capitalist precepts in the recent process of urbanization of the region and seeks to relate the transformations that occurred in the Cerrado territory from the modernization imposed by capitalism, through an urban restructuring through which the Midwest region. has been going through the mid-twentieth century with the process of expanding the economic frontier over the Amazon. It starts from the understanding that the Brazilian State fits the demands of the world capitalism through the implantation of the urban-industrial model. Regional development policies implemented mainly after the 1940s made it possible to capture this territory through capital, and state arrangements made it possible to invest in infrastructure, create planning agencies, and foster population migration flows towards polarizing cities. The approach method is the Historical and the detached analysis is the Dialectic, and this work is the partial result of a component research of the projects "PGPSE / CAPES Territorial Development and Sociobiodiversity: perspectives for the Cerrado World" and "PROCAD / CAPES Territory". , Environment and Rural-Urban-Regional Dynamics in the Brazilian Amazon".
\end{abstract}

Keywords: Capitalist frontier. Regional development policies. Urbanization. Cerrado and Amazon. 


\section{INTRODUÇÃO}

Os esforços para a integração e a incorporação da região centro-norte-amazônica brasileira à dinâmica do mercado capitalista tiveram início no limiar do século XX. Esse movimento resultou do amadurecimento e da consolidação do mercado nacional, a partir da formação de uma "região concentrada" (SANTOS, 2008b) em torno da cidade de São Paulo, que organizou a partir do final do século XIX a rede urbana nacional.

O surgimento de novas demandas agrícolas do mercado europeu, a estagnação do desenvolvimento técnico, a dispersão demográfica em zonas rurais e o clima/solo impróprios para o cultivo de novos produtos de interesse no mercado são alguns fatores que explicam a decadência do nordeste, especialmente de Salvador, e a assunção do sudeste e da cidade de São Paulo (SANTOS, 2008b; BECKER, [1972] 2015). Esta possuía o ambiente apropriado para o cultivo do café, se beneficiou com a proximidade da capital federal, instalada na cidade do Rio de Janeiro, e dos efeitos de dispersão provocados pela Segunda Revolução Industrial, tendo herdado não só a prerrogativa de centralizar a rede nacional de comunicação e de transportes, como também de se industrializar modernamente a partir da transformação primária.

Com essas premissas São Paulo se urbanizou muito rapidamente, tendo num curtíssimo intervalo de tempo se tornado num dos maiores fenômenos urbanos mundiais. Para se ter ideia, Santos (2008a) revela que em 1872 a cidade possuía pouco mais do que 31 mil habitantes e apenas 28 anos depois, em 1900, já contava com uma população de mais de 239 mil habitantes. Assim, a capital paulista tornou-se a "core region" de uma "periferia dinâmica" (BECKER, [1972] 2015), ou o centro da "região concentrada" (SANTOS, 2008b), centralizando gente, agricultura de ponta e indústrias, o sistema financeiro e a distribuição comercial, as informações e o comando da rede de transportes, o trabalho e o capital.

Daí decorre o surgimento das demais regiões brasileiras, marcadas pela condição periférica. Santos (2008b) identificou três regiões, sendo elas a Nordeste, marcada pela existência de um meio mecanizado de baixa densidade e com a circulação das pessoas, produtos e informações limitada pela agricultura pouco intensiva e pela estrutura da propriedade; a Centro-Oeste, que inclui além dos estados atuais o Tocantins, caracterizado por uma ocupação recente num território "pré-técnico", dominado hoje pela rarefação contrastante com a informação, sendo um espaço dominado pelo meio técnico-científico-informacional; e a Amazônia, espaço de rarefação demográfica e baixa densidade técnica, constituído por "cidades-cogumelos", núcleos multifuncionais que cobrem vastas áreas marcadas pela tradicionalidade do uso da terra e sustentam as fazendas modernas em sua articulação com o mundo capitalista.

Por seu turno, mesmo identificando também três outras regiões, Becker ([1972] 2015) se distingue de Santos quanto às áreas do território nacional pertencentes a cada região. Para a autora, o século XIX representou o fim da longa fase de exploração de recursos, cedendo espaço para a fase de substituição de importações e, depois, para a da integração nacional. Com a economia notadamente associada à das metrópoles europeias, as regiões que se erigem das interações espaciais brasileiras são dominadas pela lógica centro-periferia.

A primeira região a se opor à região periférica dinâmica é a que essa substituiu em termos de dinamismo: a periférica deprimida, que coincide com a região nordestina. Já o norte de Minas Gerais e o sul do Rio Grande do Sul são identificados pela autora como região periférica de lento crescimento, marcado pela condição de "retaguarda" da primeira e produtora de gado, seus derivados e hortifrutigranjeiro para abastecimento da região dinâmica. Por fim, a região de novas oportunidades, ou "fronteira de recursos", que envolve parte significativa do Centro-Oeste, pedaço do Maranhão e praticamente toda a Amazônia. Para Becker ([1972] 2015, p. 35), "em virtude do alto valor de seus recursos naturais e do seu despovoamento, é mais capaz de absorver inovações e atrair efeitos de difusão do que de perder recursos sob efeitos de drenagem".

É sobre essa região de novas oportunidades, na condição de fronteira de recursos, que esse artigo intenciona tratar, concebendo-a como região Centro-Norte, que articula o Cerrado e a Amazônia brasileiros. A intensidade de sua articulação à dinâmica capitalista é fenômeno recente, oriundo da era da globalização enquanto meio técnico-científico-informacional e se contrapõe à lógica de usos tradicionais da terra por parte das comunidades sitiantes e organizadas no contexto da fronteira, atenuando as desigualdades socioterritoriais. Contudo, as políticas de desenvolvimento regional incidentes na região, especialmente na fase de substituição de importações e da integração nacional, 
focaram em desenvolver uma frente pioneira para satisfazer ao interesse do capital.

Para fazer essa leitura utilizou-se como metodologia o método histórico, sobre o qual se procede à análise dialética. O cotejamento bibliográfico para a revisitação geo-histórica é recurso fundamental, uma vez que se intenciona compreender a dinâmica sócio-territorial atual (século XXI) do centronorte-amazônico/Amazônia Legal.

\section{O CENTRO-NORTE-AMAZÔNICO COMO REGIÃO DE NOVAS OPORTUNIDADES}

Em 1972, praticamente cinco décadas passadas, numa comunicação ao I Encontro de Geógrafos em Presidente Prudente - SP, Bertha Becker ousou denominar uma vasta região do território brasileiro, constituído pela maior porção das macrorregiões Centro-Oeste e Norte (além de um pedacinho do Nordeste), de região de novas oportunidades (BECKER, [1972] 2015).

Esse exercício foi feito na sua tentativa de buscar compreender o desenvolvimento desigual das regiões brasileiras, na qual a autora, com base na teoria do sistema espacial de John Friedmann, apresenta o seu modelo de regionalização do Brasil face à dicotomia centro-periferia. Como vimos acima, das quatro regiões identificadas pela autora, apenas uma não recebeu dela o título de "periferia": a região da fronteira de recursos, ou de novas oportunidades. Sem embargo, a autora depositou forte crença de que essa região incorporaria um renovado dinamismo no processo de desenvolvimento regional brasileiro.

A sua crença não partia do vazio: pelo olhar atento da pesquisadora, pelo menos três fenômenos lhe chamava atenção para o centro-norte-amazônico. O primeiro deles dizia respeito ao conjunto das políticas públicas de desenvolvimento regional, especialmente do Governo Federal, frente ao seu conteúdo e seus objetivos. Em que pese tais políticas terem sido formuladas e implementadas ao longo de todo o século XX, foi mesmo a partir de 1960, no período identificado por Becker ([1972] 2015) de integração nacional, que essas se intensificam no processo de transformação do território fruto da análise. O segundo fenômeno diz respeito às contradições dessa região, especialmente a materializada no Norte e expressa na potencialidade natural versus baixa densidade demográfica versus dificuldades físicas de assentamento e transportes terrestres versus conjunto dos investimentos. Por fim, o terceiro fenômeno diz respeito ao interesse do capital internacional em investir no Brasil em commodities e minérios e a indução desses investimentos pelo Governo Federal, via políticas públicas, para essa região.

Resulta disso uma segunda frente da velha marcha para o oeste, dinamizada a partir da década de 1960, fazendo avançar a fronteira econômica e social ${ }^{1}$ do país para a Amazônia Legal, constituída pelos Estados do Norte, além de parte do Maranhão (NE) e do Mato Grosso (CO). Nesses termos, o conceito de fronteira com o qual se lida aqui não corresponde ao de sua instância físico-territorial a separar Estados Nacionais, mas àquele cunhado por Martins (1975), que analisa a relação socioespacial contraditória que se instala com o avanço das frentes pioneira e de expansão.

Martins (2009) relaciona sete conceitos objetivos e articulados de fronteira:

1. Expansão da sociedade nacional sobre os territórios ocupados por povos indígenas (2009, p. 9);

2. Cenário altamente conflitivo de humanidades que não forjam no seu encontro o homem e o humano idílicos da tradição filosófica (p. 9);

3. Cenário de intolerância, ambição e morte constituído pelos diferentes grupos dos chamados "civilizados", impulsionados pela frente de expansão (p. 9);

4. Lugar de elaboração de uma residual concepção de esperança, marcado pela definição de um tempo de redenção, justiça, alegria e fartura (p. 10);

5. Aos grupos indígenas, a fronteira é ponto limite de territórios que se redefinem continuamente, disputados de diferentes modos por diferentes grupos humanos (p. 10);

\footnotetext{
1 Opta-se aqui pelo termo fronteira social e não fronteira demográfica pelo entendimento de que a região sempre contou com a presença humana, muito antes de qualquer esforço de "colonização" desprendido pela ocupação europeia. A presença de grupos indígenas é disseminada por toda região, de modo que a frente de expansão resultante desse processo de indução fez avançar sobre a região novas realidades sociais.
} 
6. Linha que separa cultura e natureza, o homem do animal, quem é humano e quem não o é (p. 10);

7. Por fim, de sua perspectiva de cientista, o autor compreende a fronteira como "o lugar privilegiado da observação sociológica e do conhecimento sobre os conflitos e dificuldades próprios da constituição do humano no encontro de sociedades que vivem no seu limite e no limiar da história" (p. 10).

Essa fronteira, constituída no avanço das relações capitalistas de produção sobre os espaços nacionais ocupados tradicionalmente por povos indígenas (a figura 1 apresenta a realidade atual da presença indígena na região) e outros povos e comunidades tradicionais, como os camponeses, seringueiros/extrativistas, ribeirinhos etc. (conforme demonstra a figura 2), é formada pela associação de interesses entre capital e Estado, que desprendem uma frente pioneira caracterizada por investimentos de infraestrutura sobre um novo espaço desejado à extensão da produção capitalista. Porém, há um contingente social presente no além-fronteira caracterizado pela ocupação de vários grupos sociais num espaço ainda não dominado pelas relações capitalistas, mobilizados pelas possíveis oportunidades de melhoria das condições de vida pelo simples fato de se ter o acesso à terra. Trata-se da frente de expansão, movimento realizado por grupos sociais que, no geral, lançam mão de práticas produtivas tradicionais.

Figura 1 - Brasil: Distribuição dos territórios indígenas, 2020

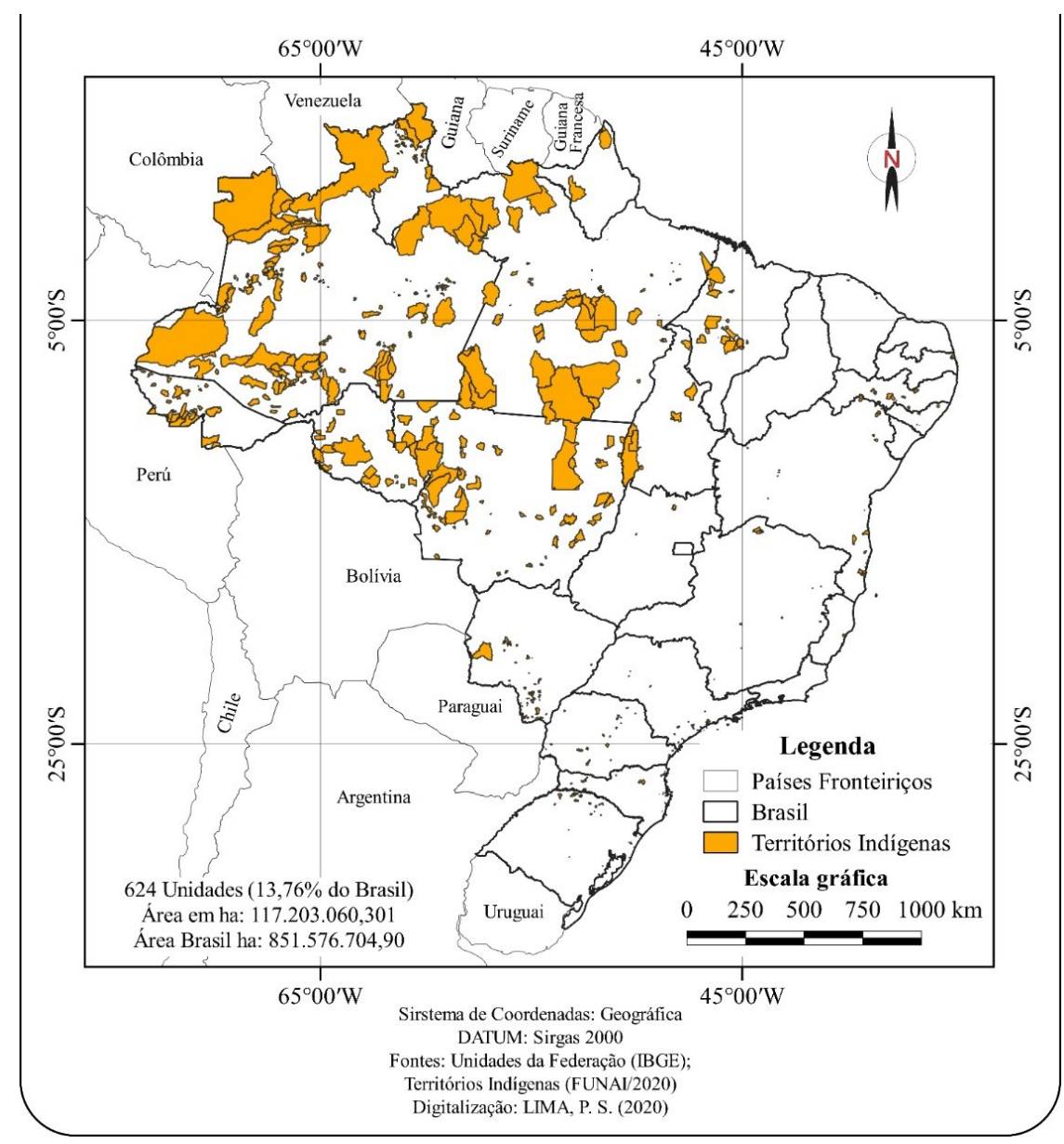

Fonte: OLIVEIRA et al (2020). 
Figura 2 - Brasil: Áreas de unidades de conservação e comunidades tradicionais, 2020

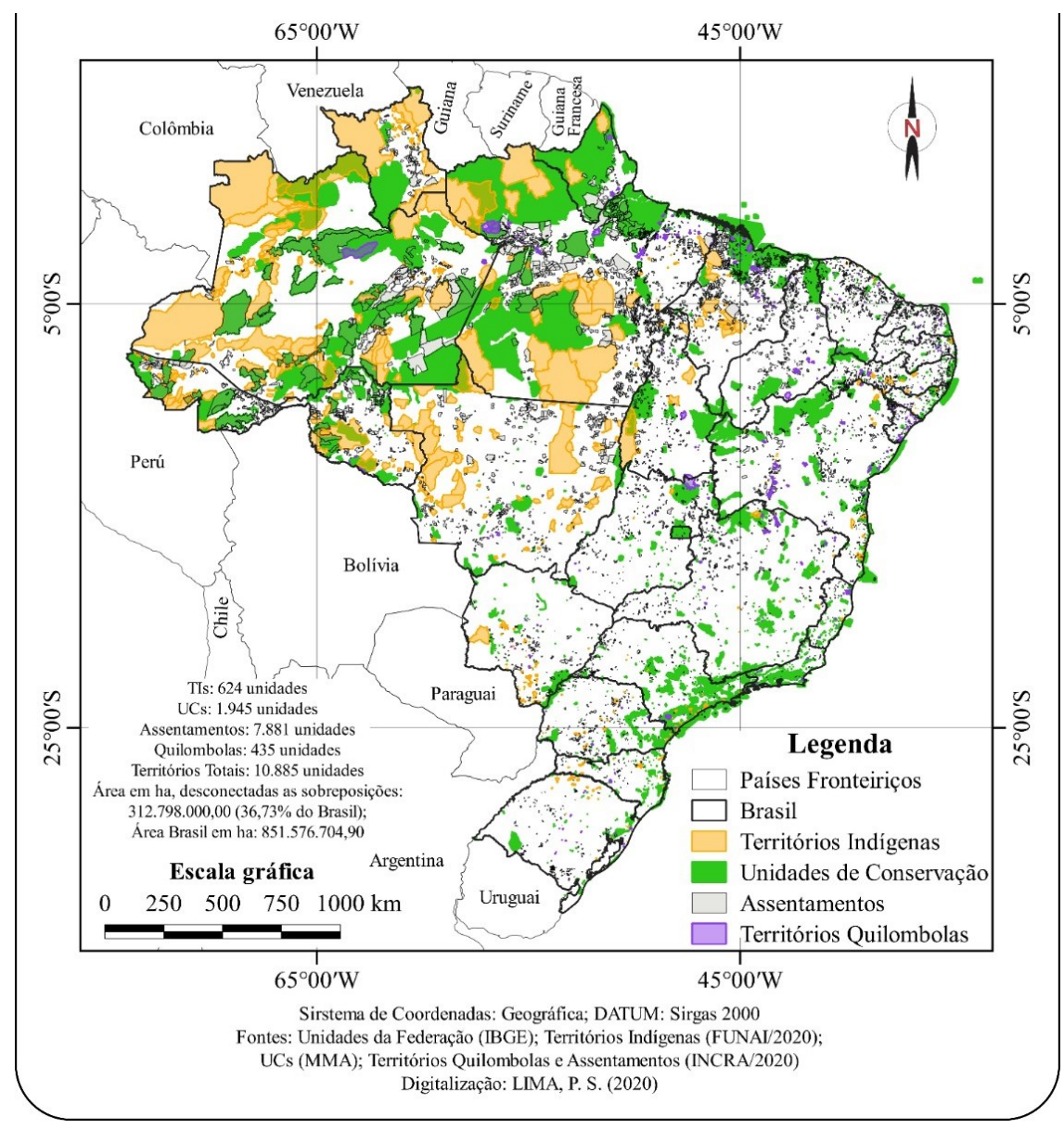

Fonte: OLIVEIRA et al (2020).

A fronteira é, pois, um lugar de alteridade (MARTINS, 1996) e nela o pioneiro que chega desejoso para se afirmar se dispõe a desprender a violência para tanto, fazendo desse espaço ao mesmo tempo um lócus de encontro e de desencontro, de reconhecimento e de negação, de oportunidade e de violência. Isso ocorre no Brasil na última região do país a ampliar a sua mecanização, marcada pela vastidão espacial num contexto de floresta e por pontos nucleares de ocupação demográfica,

\begin{abstract}
que exercem um fraco papel de centralidade sobre parcelas limitadas do espaço, cujo controle depende, na maior parte da navegação dos rios. As exceções são as áreas onde se instalam fazendas modernas, sequiosas de fluidez e exigentes de relações, levando ao rápido crescimento de núcleos urbanos tornados multifuncionais e exercendo um comeando sobre vastas áreas. Essas áreas agrícolas e essas cidades-cogumelo já constituem um indício da penetração, na região, dos nexos da globalização, sob cuja égide as conexões com as áreas mais dinâmicas do país são asseguradas mediante a disseminação dos recursos das telecomunicações modernas (SANTOS e SILVEIRA, 2008, 272-273).
\end{abstract}

Dessa forma, enquanto entre as décadas de 1960 e 1980 os grandes centros urbanos se metropolizavam no Brasil, na região amazônica (centro-norte; Amazônia Legal) as frentes pioneiras cuidavam de criar as condições para a sua exploração capitalista, articulando-a à divisão regional do trabalho a partir de sua formação socioespacial específica. A dinâmica capitalista que se apropriou dos territórios do Cerrado e da Amazônia provocou uma reestruturação das respectivas redes urbana regionais, enfatizando o papel das cidades médias que se estruturaram diante dessa nova realidade, especialmente entre as décadas de 1980 e 2010.

As fronteiras econômicas se abriram ao capital, o espaço amazônico se valorizou por meio dos novos eixos rodoviários que se formaram, concentrando o povoamento ao longo de suas margens, desenvolvendo cidades e dando surgimento a outras, incorporando as novas vias de circulação aos já 
tradicionais eixos fluviais. Nesse contexto, as cidades médias passaram por intensas modificações, estritamente relacionadas com os interesses e as próprias estratégias locacionais do capital, particularmente quanto ao acirramento da concorrência no contexto atual e a necessidade de manutenção do padrão de acumulação alcançado em décadas anteriores, sobretudo após a Segunda Guerra Mundial.

Trata-se de núcleos urbanos que passaram por um processo de revigoramento oriundo da valorização econômica de produtos locais e da intensificação da pressão de serviços provenientes da abertura de rodovias de penetração. Por isso, se tornaram cidades mais consolidadas e irradiadoras de dinamismo econômico, que reafirmaram centralidades regionais orientadas pelo capital.

Tais definições fizeram dessa região um espaço contraditório, marcado pelo conflito (muitas vezes de repugnante violência física) entre o civilizado/pioneiro/forasteiro e o indígena/autóctone, entre a modernização e a biodiversidade, entre o capital e a sociobiodiversidade.

Sociobiodiversidade é um termo cunhado entre os anos de 2007 e 2009 a partir do esforço interinstitucional dos ministérios brasileiros do Meio Ambiente, do Desenvolvimento Agrário e do Desenvolvimento Social, em associação com organizações da sociedade civil e da academia brasileiras, que designa a produção e os serviços realizados pelos chamados "povos e comunidades tradicionais" no contexto da biodiversidade (MDA, MMA e MDA, 2009).

A base para a constituição desse conceito foi a luta de organizações da sociedade civil ambientais e por direitos étnicos ao longo de pouco mais de duas décadas (1985-2007), visando ao reconhecimento social e, por decorrência, por direitos dos povos viventes no contexto da biodiversidade, situados fundamentalmente (mas não exclusivamente), no Centro-Norte-Amazônico (biomas Cerrado e Amazônico). A culminância desse processo, mediado por pesquisadores e acadêmicos das Ciências Humanas e Ambientais (DIEGUES, 1999; DIEGUES, 2000; DIEGUES 2005; LITTLE, 2005; BARRETO FILHO, 2006) se deu com a instituição do Decreto N. 6.040, da Presidência da República Federativa Brasileira, de 07 de fevereiro de 2007, criando a Política Nacional de Desenvolvimento Sustentável dos Povos e Comunidades Tradicionais.

Se, por um lado, esse decreto reconhece e identifica os povos e as comunidades tradicionais brasileiros, fundamentando a garantia jurídica de sua territorialidade, por outro esses estudos avançaram no sentido de orientar o reconhecimento do saber tradicional e a sua relação com biodiversidade, baseada no manejo sustentável dos recursos naturais (DIEGUES, 2005), o que é fundamental para a reprodução dos biomas onde essas comunidades e povos se inserem. Assim, lógica produtiva predominante no contexto da sociobiodiversidade é a da relação profunda com a natureza; da racionalidade econômico-produtiva baseada na unidade familiar doméstica ou comunal, nas relações de parentesco ou no compadrio; na relação com o território e com a territorialidade por várias gerações; e nas inter-relações com os outros grupos da região e autoidentificação (CRUZ, 2012).

É, pois, essa realidade contraditória, dialética e, ao mesmo tempo, fenomenal, refletida nessas duas primeiras décadas do século XXI, que se intenciona lançar as bases para a compreensão.

\section{POLÍTICAS REGIONAIS NA AMAZÔNIA BRASILEIRA}

No campo científico da Geografia, as políticas públicas de investimento para o desenvolvimento regional são conhecidas como políticas territoriais, isto é, enquanto atividade planejadora do Estado voltado ao enfoque regional (COSTA, 1997).

Em que pese as políticas de desenvolvimento regional no Brasil serem formuladas e implementadas desde o início do século XX, o planejamento territorial sistemático inicia-se a partir de $1930 \mathrm{com}$ a chegada de Getúlio Vargas à Presidência da República (SANTOS, 2013). Após a Revolução de 1930, desencadeia-se um intenso fortalecimento da inserção do país no sistema capitalista industrial. Isso fez com que o Estado passasse a desempenhar um papel centralizador político-administrativo. Assim, surge uma burguesia industrial nacional forte. Para Santos (2013) as políticas territoriais a partir de Vargas exigem do Estado

[...] uma ação mais racional, moderno e centralizador gerando um re-arranjo territorial [...] A partir do estabelecimento desta política territorial do governo federal, iniciou-se um processo de divisão regional do território nacional para garantir o desenvolvimento do capitalismo industrial que estava chegando ao país. O governo federal começou instituir regiões por meio de decretos (SANTOS, 2013, p. 100). 
A partir de então, algumas das políticas territoriais instituídas tinham explícita em seu planejamento a ocupação do Oeste - marcado pelo discurso ideológico neocolonialista, com o lema "Marcha para o Oeste" - e da Amazônia. Fato este que, em 1953 é criada a SPVEA - Superintendência do Plano de Valorização Econômica da Amazônia, instituída pela Lei $n^{\circ}$ 1.806, de 6 de Janeiro de 1953. Simultaneamente, com a criação desta superintendência criou-se também a Amazônia Legal (Decreto-Lei de agosto de 1953).

Em busca de uma consolidação do desenvolvimento regional na Amazônia e impregnado da ideologia desenvolvimentista, Vargas e, posteriormente, Juscelino Kubitschek instituem vários incentivos fiscais e políticas de investimento na região (SANTOS, 2013). A sua concretização foi concebida através de decretos e consolidada pelas políticas públicas de investimento provenientes da SPVEA, Planos Nacionais de desenvolvimentos, Plano de Desenvolvimento da Amazônia, entre outros. Lira (2011, p. 40) alerta que a SPVEA "[...] marca de maneira planejada e institucionalizada, a presença do Estado, controlador e 'organizador' das finanças públicas na Amazônia." Com as medidas feitas pelo governo, por meio da SPVEA, a região passa a ter atuação direta do Estado. No entanto, em 1966, no governo de Castelo Branco, a SPVEA foi substituída pela SUDAM Superintendência de Desenvolvimento da Amazônia.

A SUDAM é uma autarquia governamental, que tem por objetivo principal promover o desenvolvimento da região Amazônica por meio da geração de incentivos fiscais e financeiros capazes de atrair investidores privados, nacionais e internacionais. Santos (2013) assevera que a atuação da SUDAM atende diretamente aos objetivos, diretrizes e instrumentos da Política de Desenvolvimento Nacional Integrada e do Plano de Desenvolvimento da Amazônia. Segundo o mesmo, tal política é executada "[...] em articulação com o Conselho Deliberativo para o Desenvolvimento da Amazônia, órgãos e entidades públicas dos Governos federal, estaduais e municipais que atuam na região e a sociedade civil organizada" (SANTOS, 2013, p. 143).

É nesse cenário que, sob o prisma do capitalismo, a Amazônia Legal se materializa. A mesma é uma região arquitetada por um recorte espacial que engloba várias unidades federativas, sem levar em conta as características morfogeológicas, de vegetação ou geográficas, mas eminentemente para fins político-econômicos. Sua atual área de abrangência é constituída por nove estados da federação, sendo: Acre, Amapá, Amazonas, Mato Grosso, Pará, Rondônia, Roraima, Tocantins e parte do Maranhão (até a oeste do meridiano de $44^{\circ}$ ), totalizando uma área de cerca de $5.217 .423 \mathrm{~km}^{2}$, correspondente a aproximadamente $61 \%$ do território brasileiro.

É interessante observar que três regiões brasileiras compreendem a cobertura da Amazônia Legal, respectivamente: Norte; Nordeste; Centro-Oeste. Essa configuração corrobora com as ideias de Lira (2011) e Oliveira (1991) de que a Amazônia Legal é um território planejado pela burocracia administrativa do Regime Militar. Para estes, esta região nada mais é do que uma reinvenção, ou melhor, uma (re)articulação de um território amazônico, criado e/ou recriado no gabinete dos governos militares sob a lógica do capitalismo num processo de interiorização e ocupação da região.

Desse modo, a Amazônia Legal seria uma (re)criação de uma região e a dilatação das áreas de ocorrências da floresta, em uma tentativa de ocupar espaços que erradamente foram considerados vazios (LIRA, 2011). Uma articulação geopolítica de conteúdo modernizador, feita pelos promotores do Regime Militar e construída de forma muito racional por meio da articulação de interesses nacionais e internacionais. Uma aliança entre Estado e capital estrangeiro, ou, segundo Becker e Egler (1994), uma aliança entre capital privado interno, externo e público, principalmente nos governos militares.

Lira (2011, p. 28) afirma que a "[...] Amazônia brasileira e Amazônia Legal dialeticamente, se contradizem, se confirmam e se negam, dentro de um contexto onde se define a natureza da geografia e as ideologias geográficas" (LIRA, 2011, p. 28). Para o mesmo existe um embate dialético entre a Amazônia brasileira (do ribeirinho, do indígena, do seringueiro, do posseiro) com a Amazônia Legal (do capital e da tecnologia), que faz surgir a "Amazônia llegal", representação do conflito que se estabelece no território, impetrada pelo modo de produção capitalista.

Assim, ao discutir as políticas desenvolvimentistas voltadas para a Amazônia, o autor verifica a presença de "várias Amazônias" dentro da mesma região, onde apesar de comporem o mesmo território, há a necessidade de desassociá-las. Segundo este autor:

[por] Amazônia Brasileira estou me referindo à região visível, um território palpável, uma região que por se já é uma região onde o homem do lugar sinta e conheça sua 
geografia, enfim, uma região que não necessite de instrumentos técnicos e/ou ideologias para definir seus contornos [...]. a Amazônia Legal é uma região criada pelos governos militares e/ou paramilitares, com o intuito de reafirmar a soberania nacional na região e desenvolvê-la de maneira "segura". Tudo isso sobre o patrocínio do capital estrangeiro, (liberalista) encontrando neste "novo" tipo de parceria, uma brecha para apropriar-se das riquezas minerais e vegetais da verdadeira Amazônia brasileira (LIRA, 2011, p. 28-29)

Partindo dessas discussões é importante destacar os principais programas institucionalizados para região. Como já explanado, foi por meio dos Planos Nacionais de Desenvolvimento que as políticas de desenvolvimento para a região amazônica se deram. Tais planos sedimentaram as diretrizes básicas para os programas de integração e desenvolvimento da região amazônica brasileira, arquitetada, sobretudo, pelo Regime Militar.

Para Oliveira (1991, p. 89) à Amazônia e ao Planalto Central estava reservada a "[...] estratégia dos polos agropecuários e agrominerais, com dupla finalidade: abrir o acesso às riquezas naturais aos grandes grupos econômicos e reorientar os fluxos migratórios predominantes na direção Nordeste/Sudeste para Nordeste/Amazônia". Para isso, o projeto de integração nacional precisava integrar a região amazônica ao contexto nacional e, por decorrência, ao cenário mundial. Precisava necessariamente de uma ocupação demográfica e econômica de forma planejada.

Segundo Santos (2013) as políticas territoriais da Amazônia foram fomentadas a partir da criação de polos de desenvolvimento, com a finalidade de estimular

[...] o processo de desenvolvimento, urbanização e, sobretudo assegurar a geopolítica territorial do capital na região. Os programas de desenvolvimento como o Polo-Centro, Polo-Amazônia, etc. foram instituídos a partir de políticas de desenvolvimento baseada na filosofia das teorias locacionais. Isto é, estabeleceu-se um desenvolvimento polarizado ou de formação de pólos de crescimento como propõe François Perroux (SANTOS, 2013, p. 147).

O I Plano Nacional de Desenvolvimento - I PND (1972/74) já tinha como constituição básica a "ocupação dos espaços vazios", uma vez que os Militares queriam preenche-los, isto é, garantir esforços estratégicos para ocupar os espaços, com empreendimentos capitalistas na região (Bolwerk, 2014). É neste prisma que surge em 1974 o POLAMAZÔNIA (Programa de Polos Agropecuários e Agrominerais da Amazônia) criado por meio do Decreto n 74.607 de 25 de setembro de 1974. Este programa veio para territorializar os grandes monopólios da Amazônia.

Vejamos o que diz o Decreto $n^{\circ} 74.607$,

Art. $1^{\circ}$ É criado o Programa de Pólos Agropecuários e Agrominerais da Amazônia (POLAMAZÔNIA), com a finalidade de promover o aproveitamento integrado das potencialidades agropecuárias, agro-industriais, florestais e minerais, em áreas prioritárias da Amazônia (BRASIL, Decreto $n^{\circ} 74.607,1974$ ).

Os planos federais previam a implantação de diversos polos de desenvolvimento na Amazônia brasileira, com destaque para a produção mineral. Segundo Monteiro (2005)

\begin{abstract}
Ancoravam-se, portanto, numa visão de desenvolvimento regional que tinha por fundamento a necessidade de concentração espacial de capitais, capazes de produzir desequilíbrios, e, em decorrência destes, impulsionar processos de desenvolvimento por meio do surgimento de uma cadeia de ligações para frente e para trás das atividades produtivas consideradas "chave". Alguns dos pólos que integravam o Polamazônia eram Carajás, Trombetas e Amapá. Este programa criou os pólos de Carajás, Trombetas e do Amapá (MONTEIRO, 2005, p. 188).
\end{abstract}

Segundo Santos (2013) ao contrário do que se pretendia (uma "concentração descentralizada" de desenvolvimento na região) o resultado foi "[...] o aumento das disparidades do desenvolvimento inter e intra-regional". Isto gerou a ampliação das desigualdades sociais e o motivo é simples: a periferia tornou-se mais dependente do centro, tanto em nível nacional como também internacional.

Já o II Plano Nacional de Desenvolvimento - II PND (1975/79) tinha a finalidade de articular a exploração de minérios com o potencial hidroelétrico da Amazônia Oriental. Esse PND delineava uma Política de Desenvolvimento de Recursos Florestais e Uso Racional dos Solos da Amazônia como o objetivo principal de "transformar a exploração madeireira numa atividade planejada, institucionalizada e permanente" (OLIVEIRA, 1991, p. 93). Ainda no ventre do II PND é criado o POLOCENTRO (Programa de Desenvolvimento dos Cerrados) por meio do Decreto $n^{\circ} 75.320$ de 29 
de janeiro de 1975. Este programa buscava desenvolver no Brasil Central um polo de desenvolvimento baseado no uso de práticas agrícolas modernas e de sua integração com o mercado (interno e externo), através de assistência técnica, financeira e de infraestrutura. No caminho inverso, desestimulava a agricultura de subsistência.

Santos (2013, p. 149) assevera que em nível ideológico, o POLOCENTRO procurava "repassar a ideia de que a principal justificativa dos programas de desenvolvimento agrário seria o mais eficiente padrão de desenvolvimento social e bem-estar das populações atingidas." No entanto, o objetivo era, de fato, conquistar o Cerrado, atingindo frações territoriais mato-grossenses e goianas cobertas pelo Cerrado na área da Amazônia Legal e no Centro-Oeste (SANTOS, 2013).

Segundo Bolwerk (2014, p. 38), o POLOCENTRO funcionava como "[...] apoio do governo militar para alavancar as políticas de entrada de capital na região, bem como introduzir novas rotas de migrações numa área extensa geograficamente." Outro programa criado com essa finalidade foi o PRODECER Programa Nipo-Brasileiro de Cooperação para o Desenvolvimento Agrícola da Região do Cerrado. Este programa foi criado a partir do acordo bilateral entre o governo brasileiro e o japonês em 1974, durante o governo do Marechal Geisel. Esse acordo visava principalmente à cooperação técnica e econômica para o desenvolvimento da área do cerrado.

O PRODECER atuou no cerrado do Centro-Oeste e na Amazônia Legal e visava, de acordo com Oliveira (1991, p. 94), "à produção de arroz e, particularmente, de soja, volta para a exportação, principalmente para o Japão".

PRODECER, POLOCENTRO e POLAMAZÔNIA partem de uma concepção de desenvolvimento polarizado, fruto das políticas públicas do Estado Keynesiano. Em suma, as políticas deliberadas por estes programas de investimentos em sua maioria se dirigiam diretamente ao grande capital (SANTOS, 2013).

Num contexto mais recente, pensando em reforçar as políticas regionais voltadas para redução das desigualdades sociais inter e intrarregionais, o Estado brasileiro criou a Política Nacional de Desenvolvimento Regional (PNDR), instituída pelo Decreto de lei n 6.047, de 22 de fevereiro de 2007 (Brasil, 2007). Esse novo instrumento político é considerado nacional porque, diferente das políticas regionais anteriores, como a SUDAM e a SUDENE, abrange todo o território nacional e é centralizada pelo Governo Federal, representado pelo Ministério da Integração Nacional. Arrais (2009) argumenta que

\begin{abstract}
A PNDR demonstra o retrato regional brasileiro, focando regiões urbanas e rurais, regiões estratégicas para a segurança nacional, bem como regiões com fragilidade ambiental e social. Essa complexidade dos arranjos, entretanto, esbarra em nossa tradição política centralizadora, por um lado, mas também na concepção estadualista que impõe dificuldades na gestão financeira das políticas nacionais com foco regional (ARRAIS, 2009, p. 4-5).
\end{abstract}

Alguns autores afirmam que apesar da PNDR ser nacional, a atuação no território não poderia ser homogênea, já que partiu do reconhecimento da existência da desigualdade regional. Arrais (2009, p. 4) assevera que "[...] a visão territorial fundamenta-se em uma tipologia que considerou, no nível microrregional, o rendimento domiciliar médio e o crescimento do PIB per capita, o que resultou na classificação das microrregiões brasileiras como baixa renda, estagnadas, dinâmicas e alta renda"

Essa classificação gerou o Mapa das Tipologias da PNDR. Esse mapa traduz a diversidade regional no Brasil, rompendo, em uma primeira leitura, com a visão de oposição homogênea entre o Nordeste "atrasado" e um Sudeste "moderno".

\title{
CONSIDERAÇÕES FINAIS
}

A partir da década de 1960 o Cerrado passou por uma ressignificação na sua representação enquanto espaço que pudesse servir à dinâmica capitalista. Até então, as terras de Cerrado, especialmente nos Estados de Goiás, Mato Grosso e Tocantins, eram tidas como terras ruins, sendo assim aproveitadas basicamente para a pecuária extensiva. Porém, a consolidação do mercado nacional e a necessidade do Centro-Sul do país, liderado por São Paulo, de incorporar novas áreas produtivas para a produção de alimentos que atendessem às suas demandas internas provocou uma modernização do campo no Cerrado. 
Novas técnicas agrícolas, como a introdução de máquinas, e a utilização de insumos estimulantes e corretores do solo fizeram do Centro-Oeste brasileiro um novo eldorado da produção agrícola nacional. Obviamente, na contramão dessa condição, o Cerrado foi gradativamente sendo descerrado... O desflorestamento na região atingiu, nos 50 anos entre as décadas de 1960 e 2000, patamares assustadores, conforme se pode consultar no sítio Observatório da Terra, do INPE Instituto Nacional de Pesquisas Espaciais, vinculado à Presidência da República.

Projetos de desenvolvimento da agricultura (como é o caso do MATOPIBA) constituem ameaça futura à incidência do bioma Cerrado e à preservação do bioma Floresta Amazônica. Não está se falando aqui de ações voluntárias; fala-se de ações coordenadas pelo Estado, o que as classifica como políticas públicas. Obviamente, isso soa contraditório, uma vez que se choca com o discurso de controle do desmatamento e da preservação dos biomas.

A partir da segunda metade da década de 2000 o Brasil registrou um maior controle no desmatamento do Cerrado. É o que demonstram os dados revelados pelo INPE. Porém, o aumento exponencial da agricultura da soja nesse período fez avançar sobre a Amazônia as novas áreas agricultáveis, colocando pressão e risco à floresta. É o que demonstra o gráfico a seguir.

Figura 3 - Amazônia: Evolução da produção de grãos

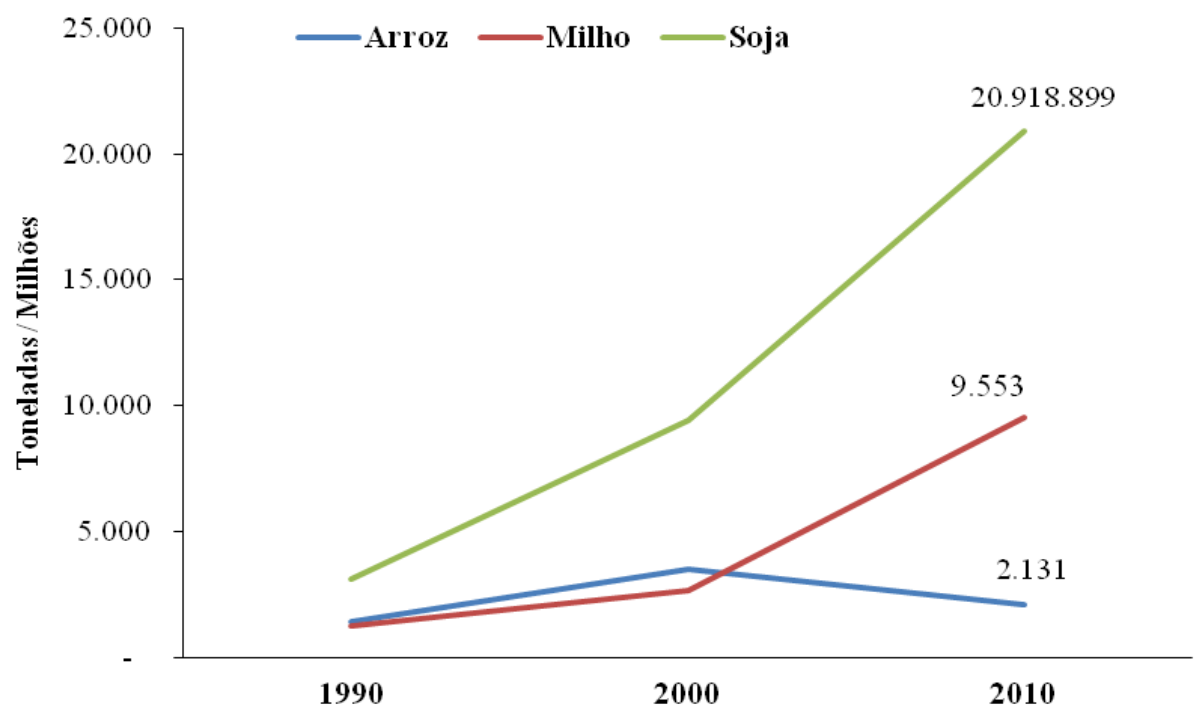

Fonte: IBGE/Produção Agrícola Municipal (2012). Organização: SILVA, 2015.

Por decorrência, enquanto se conteve o desmatamento do Cerrado, aumentou-se o desmatamento sobre a floresta Amazônica, principalmente na borda da região da Amazônia Legal, no entorno das principais rodovias que cortam a região.

O que se percebe com isso é que o agronegócio brasileiro tem provocado um "efeito cupim" sobre dois dos mais importantes biomas mundiais: o Cerrado e a Floresta Amazônica. Depois de ter carcomido entre 1960 e 2000 as matas que são próprias do Cerrado, o "cupim" do agronegócio encontra-se hoje nas bordas da Floresta Amazônica e bota pressão para entrar. Por sua vez, o Estado brasileiro "bate cabeça" buscando resolver o dilema de proteger e preservar os biomas e, ao mesmo tempo, contemplar os interesses do capital agrário constituído por produtores nacionais em associação com indústrias de transformação internacionais.

Escapa à percepção da elite econômica brasileira a possibilidade de investir o seu capital em patentes e explorações possíveis pela manutenção da floresta e do Cerrado. A biodiversidade desses dois biomas gera "n" situações de riqueza a partir do que neles se pode produzir: remédios e curas; alimentos; venenos e morte; soluções em energia, para o solo, para o clima; minérios, água, vida. Grande parte da solução que o mundo espera hoje tem resposta na Floresta Amazônica e no Cerrado. Então não se trata apenas de reproduzir um discurso ambiental de preservação da floresta e da mata para combater o aquecimento global e manter o clima ameno. É mais do que isso: é também negócio e é também a vida. 
A transpiração da Floresta Amazônica produz o fenômeno dos "rios voadores", que são cursos de água atmosféricos que fazem precipitar as chuvas no Cerrado, que por sua vez funcionam como inibidoras das queimadas naturais desse bioma. A água que molha o Cerrado penetra o solo através de suas gramíneas com raízes que medem mais de um metro e não só viabilizam as três maiores bacias hidrográficas da América do Sul (Amazônia/Tocantins, São Francisco e Prata), como também abastecem importantes aquíferos, que são os reservatórios de água doce do planeta.

Sem a Floresta Amazônica não há rios voadores, e sem esses não há a possibilidade de repovoar o Cerrado. A inexistência desses dois biomas coloca em risco as maiores reservas de água doce do planeta que, agravado pela elevação do clima, produzirá inevitavelmente a alteração de sua biogeoestrutura, o que significa o começo do fim.

\section{AGRADECIMENTO}

Este trabalho é resultado parcial de uma pesquisa componente dos projetos "PGPSE/CAPES Desenvolvimento Territorial e Sociobiodiversidade: perspectivas para o mundo do Cerrado" (20152020) e "PROCAD/CAPES Território, Meio Ambiente e Dinâmicas Rural-Urbano-Regionais na Amazônia Brasileira" (2015-2020).

\section{REFERÊNCIAS}

ARRAIS, Tadeu A. Apontamentos metodológicos sobre desenvolvimento regional. Biblio 3W: Revista bibliográfica de Geografía y Ciencias Sociales da Universidad de Barcelona, Espanha, v. XIV, n. 849, 30 nov. 2009. Disponível em: <http://www.ub.edu/geocrit/b3w-849.htm> Acesso em: dez. 2013.

BARRETO FILHO, H. T. Populações tradicionais: introdução à crítica da ecologia política de uma noção. In: ADAMS, C. et. all. (orgs.). Sociedades caboclas amazônicas: modernidade e invisibilidade. São Paulo: Annablume, 2006.

BECKER, B. Amazônia. São Paulo: Ática, 1990.112p.

A Amazônia e a política ambiental brasileira. In: SANTOS, M.; BECKER, K. B. (Ed.). Território, territórios: ensaios sobre o ordenamento territorial. Rio de Janeiro: Lamparina, 2007, p. $22-40$.

. Fronteira e urbanização repensadas. In: BECKER, Bertha K. MIRANDA, BECKER, B. Revisão das políticas de ocupação da Amazônia: é possível identificar modelos para projetar cenários? Parcerias Estratégicas, Brasília, v.12, n.1, p.135-159, 2001.

BECKER, Bertha. Espaço e desenvolvimento desigual: uma percepção da década de 1970. Revista Brasileira de Geografia - IBGE, Rio de Janeiro, ano 34, n. 4, 1972 (In: VIEIRA, Ima C. G. (org.). As Amazônias de Bertha Becker: ensaios sobre Geografia e sociedade na região amazônica - vol. 1. Rio de Janeiro: Garamond, 2015.

Política regional e mobilidade da população na fronteira. Revista Brasileira de Geografia, ano 41, n. 4, 1979. 1974.

A Amazônia na estrutura espacial do Brasil. Revista Brasileira de Geografia, ano 36, n. 2,

. Agricultura e desenvolvimento no Brasil: a expansão da fronteira agrícola. Regional

Dialogue - United Nations Centre for Regional Development, Nagoya, v. 1, n. 2, 1980.

A fronteira em fins do século XX: oito proposições para um debate sobre a Amazônia. Espaço e Debates, São Paulo, n. 13, 1984, p. 59-73.

BECKER, Bertha Koiffmann; EGLER, Claúdi. Brasil: uma nova potência regional na economiamundo. $2^{\circ} \mathrm{ed}$. Rio de Janeiro: Bertrand, 1994.

BOLWERK, Diógenes Alencar. A (re)produção do espaço/ Tocantins no contexto regional. 2014. 206 f. Dissertação (Mestrado em Geografia) - Universidade Federal do Tocantins. Campus de Porto Nacional - TO: UFT, 2014. 
BRASIL. MMA, MDA, MDS. Plano Nacional das Cadeias de Produtos da Sociobiodiversidade. Brasília: MMA, 2009.

BRASIL. Senado Federal. Decreto № 74.607, de 25 de setembro de 1974. Dispõe sobre a criação do Programa de Pólos Agropecuários e Agrominerais da Amazônia (POLAMAZÔNIA). Brasília: Secretaria de Informação Legislativa, 1974. Disponível em: <http://www.2.camara.leg. br/legin/fed/decret/1970-1979/decreto-74607-25-setembro1974-423225-publicacaooriginal-1-pe.html>. Acessado em: jan. 2014.

CASTILHO, D.; CHAVEIRO, E. F. Por uma análise territorial do Cerrado. In: CASTILHO, D.; PELÁ, M. C. (orgs.). Cerrados: perspectivas e olhares. Goiânia: Ed. Vieira, 2010.

CHAVEIRO, E. F. Desenvolvimento territorial e sociobiodiversidade: perspectivas para o mundo do Cerrado. In: OLIVEIRA, A. F.; CHAVEIRO, E. F.; BRANDÃO, C. A. (orgs.). Seminário internacional Meio Ambiente, Dinâmicas Regionais e Planejamento Territorial na Amazônia e no Cerrado Anais. Porto Nacional - TO: UFT, 2017.

CHAVEIRO, E. F.; OLIVEIRA, A. F.; OLIVEIRA, U. F. Transformação em Goiás: capitalismo, modernização e novas disposições socioespaciais. Caminhos de Geografia (UFU), v.10, p. 227-234, 2009.

CHAVEIRO, E. F; CALAÇA, M. Por uma Abordagem Territorial do Cerrado Goiano. In: Marcos Aurélio Saquet; Egidio Dansero; Luciano Zanetti Pessôa Candiotto. (Org.). Geografia da e para a cooperação ao desenvolvimento territorial: experiências brasileiras e italianas. São Paulo: Expressão Popular, 2012, v. 1, p. 191-206.

CORRÊA, R. L. A Periodização da Rede Urbana da Amazônia. Revista Brasileira de Geografia, Rio de Janeiro, v. 49, n.3, p.39-68, 1987.

COSTA, Wanderlei Messias de. O Estado e as políticas territoriais no Brasil. São Paulo: Contexto, 1997.

CRUZ, V. do C. Povos e comunidades tradicionais. In: CALDART, R. S. et. all. (orgs.). Dicionário de Educação do Campo. $2^{\mathrm{a}}$ ed. Rio de Janeiro: Expressão Popular, 2012.

DIEGUES, A. C. (org.). Os saberes tradicionais e a biodiversidade no Brasil. São Paulo: NUPAUB / Brasília: MMA, 1999.

O mito moderno da natureza intocada. $3^{\mathrm{a}}$ ed. São Paulo: Hucitec, 2000.

Sociobiodiversidade. In: FERRARO JÚNIOR, L. A. (orgs.). Encontros e caminhos:

formação de educadoras(es) ambientais e coletivos educadores. Brasília: MMA, 2005.

FEARNSIDE, P. Desmatamento na Amazônia brasileira: história, índices e conseqüências.

Megadiversidade, Belo Horizonte, v.01, n.01, p. 113-123, 2005.

IANNI, O. Colonização e Contra-Reforma Agrária na Amazônia. Petrópolis: Vozes, 1979. 140 p.

INPE/Observatório da Terra. Desmatamento no bioma Cerrado. Disponível no sítio: http://www.obt.inpe.br/OBT/noticias/inpe-divulga-dados-sobre-o-desmatamento-do-bioma-cerrado. Acessado em 27/-8/2019

KOHLHEPP, G. "Conflitos de Interesse no ordenamento territorial da Amazônia brasileira". Estudos Avançados, São Paulo, v. 16, n. 45, p. 37-61, 2002.

https://doi.org/10.1590/S010340142002000200004

LIRA, Elizeu Ribeiro. A gênese de Palmas - Tocantins: a Geopolítica de (Re)Ocupação territorial na Amazônia Legal. Goiânia: Kelps, 2011.

LITTLE, P. E. Territórios sociais e povos tradicionais no Brasil. In: Anuário Antropológico 20022003. Rio de Janeiro: Tempo Brasileiro, 2005, p. 251-290.

MACHADO, L. O. Urbanisation et marché du travail en Amazonie brésilienne. In: DIAS, L. C. ; RAUD, C. (Orgs.). Villes et région au Brésil. Paris: L'Harmattan, 2000, p. 165-191.

MAHAR, D.J. Desenvolvimento econômico da Amazônia: uma analise das políticas governamentais. Rio de Janeiro: IPEA, 1978. 259p. 
MONTEIRO, Maurílio de A. Meio século de mineração industrial na Amazônia e suas complicações para o desenvolvimento regional. Estudos Avançados, vol. 19, n. 53, São Paulo, 2005, p. 187-207. https://doi.org/10.1590/S0103-40142005000100012

OLIVEIRA, Ariovaldo Umbelino de. Integrar para não entregar. Campinas-SP: Papirus, 1991.

RIBEIRO, M. A. A complexidade da rede urbana Amazônica: três dimensões de análise. Rio de Janeiro, 1998. Tese (Doutorado em Ciências) - Programa de Pós-Graduação em Geografia, Instituto de Geociências, Universidade Federal do Rio de Janeiro.

SANTOS, Milton. A urbanização brasileira. São Paulo: Hucitec, 1993.

A metamorfose do espaço habitado: fundamentos teóricos e metodológicos da Geografia. São Paulo: Hucitec, 5. ed. São Paulo, 1997.

O espaço do cidadão. $7^{\text {a }}$ ed. São Paulo: Edusp, coleção "Milton Santos - 8”, 2007.

Da totalidade ao lugar. São Paulo: Edusp, coleção "Milton Santos - 7", 2008a.

Por uma Geografia Nova: da crítica da Geografia a uma Geografia Crítica. $6^{a}$ ed. São Paulo: Edusp, coleção "Milton Santos - 2" 2008b.

A natureza do Espaço: técnica e tempo, razão e emoção. $4^{\mathrm{a}}$ ed. São Paulo: Edusp, coleção "Milton Santos - 1", 2008c. https://doi.org/10.22409/GEOgraphia1999.11.a13370

SANTOS, Roberto de S. Os condicionamentos das Políticas territoriais e do processo de territorialização dos atores hegemônicos no desenvolvimento regional e local: uma análise crítica no contexto de Tocantins. 2013. 354 f. Relatório Científico (Estágio de Pós-Doutoramento) Instituto de Estudos Socioambientais (IESA), Universidade Federal de Goiás, Campus de Goiânia GO, 2013.

SATHLER, D.; MONTE-MÓR, R. L.; CARVALHO, J. A. M. de. As redes para além dos rios: urbanização e desequilíbrios na Amazônia brasileira. Nova Economia, Belo Horizonte, v. 19, $n^{\circ} 1$, jan./abr. 2009, p. 10-39. https://doi.org/10.1590/S0103-63512009000100002

SILVA, R. G. da C. Amazônia globalizada: da fronteira agrícola ao território do agronegócio - o exemplo de Rondônia. Revista Confins, N. 23, 2015. https://doi.org/10.4000/confins.9949

SPOSITO, Maria. E. B. Capitalismo e Urbanização. São Paulo: Contexto, 1988.

. As cidades médias e os contextos econômicos contemporâneos. In: Urbanização e Cidades. Perspectivas Geográficas. São Paulo: Gasper/EDUSP, 2001. p. 609-643.

TRINDADE JÚNIOR. Saint-Clair C. da. A cidade dispersa: os novos espaços de assentamentos em Belém e a reestruturação metropolitana. 1998. Tese (Doutorado em Geografia Humana) Faculdade de Filosofia, Letras e Ciências Humanas, Universidade de São Paulo, São Paulo.

Recebido em: 20/09/2020

Aceito para publicação em: 18/11/2020 